\title{
DTC with fuzzy logic for multi-machine systems: traction applications
}

\author{
Ndoumbé Matéké Max ${ }^{1}$, Nyobe Yomé Jean Maurice², Eke Samuel ${ }^{3}$, Mouné Cédric Jordan ${ }^{4}$, \\ Alain Biboum ${ }^{5}$, Bitjoka Laurent ${ }^{6}$ \\ ${ }^{1-4}$ Laboratory of Energy, Materials, Modelling and Methods, National Higher Polytechnic School of Douala, \\ University of Douala, Douala, Cameroon \\ ${ }^{5}$ Industrial and Mechanic Engineering Department, National Advanced School of Engineering Yaounde, Yaounde, \\ Cameroon \\ ${ }^{6}$ Laboratory of Energy, Signal and Automation (LESIA), University of Ngaoundéré, Ngaoundere, Cameroon
}

\section{Article Info \\ Article history: \\ Received Mar 24, 2021 \\ Revised Sep 10, 2021 \\ Accepted Sep 17, 2021}

\section{Keywords:}

Asynchronous motor

Direct torque control

Electric vehicle

Fuzzy logic

Variable master slave control

\begin{abstract}
In this work, a direct torque control (DTC) method for multi-machine systems is applied to electric vehicles (EVs). Initially, the DTC control method associated with the model reference adaptive system (MRAS) is used for speed control, and management of the magnetic quantities is ensured by the variable master-slave control (VMSC). In order to increase the technical performance of the studied system, a DTC method has been associated with a fuzzy logic approach. These two control methods are applied to the traction chain of an electric vehicle to highlight its speed, precision, stability, and robustness metric during particular stress tests imposed on the wheel motor. The results obtained in MATLAB/Simulink software made feasible a comparison of two proposed methods based on their technical performances. It should be noted that the direct fuzzy logic torque control (DFTC) has better performance than the DTC associated with the MRAS system as a rise time reduction of 1.4 percent, an oscillation of torque, and flux amplitude of less than 9 percent, static steady-state error near zero. The DTFC control method responds favorably to electric vehicle traction chain systems by the nature of the comfort and safety provided.
\end{abstract}

This is an open access article under the CC BY-SA license.

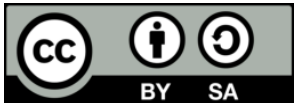

\section{Corresponding Author:}

Ndoumbé Matéké Max

Laboratory of Energy, Materials, Modelling and Methods

National Higher Polytechnic School of Douala

University of Douala PO Box 2701 Douala, Cameroon

Email: mdesmax@yahoo.fr

\section{INTRODUCTION}

With a rapid increase in energy demand and a global goal of preserving the environment by reducing greenhouse gas emissions, the new generation of electric vehicles has proven to be essential assets [1]-[3]. Thus, the development of electric mobility opens doors to new technologies, especially in the field of electric drive [4], [5]. The electric vehicle is based on electric actuators which are responsible for the traction systems mechanism. Induction machines are mostly used for this purpose due to their reliability, low cost, and great robustness [6]-[9]. The electric actuator that makes up the vehicle can only function optimally if it is driven by an adequate control system such as direct torque control (DTC) [10]. Indeed, this control system ensures a fast dynamic response of the torque and stator flux arising some drawback issues which impact the wear of engines acceleration and contribute to increasing noises in the passenger compartment. Since its invention by Takahashi and Noguchi [10], this control system has undergone several changes and 
improvements such as direct torque control associated with vector modulation (SVM-DTC), direct torque control based on artificial intelligence such as fuzzy logic (DTFC), neural networks (DTNC), and genetic algorithms [2]. Usually, the motor is controlled by a converter. When an application requires multiple motors, multiple converters must be available to supply power to motors. The multi-machine technology used for the propulsion systems of EVs offers numerous advantages over internal combustion vehicles [11]-[13]. However, its major disadvantage is related to the important volume for the overall system which generally impacts its control system. Several works have been carried out to provide effective solutions to such problems.

Nasri and Gasbaoui [6] presents an example of a developed DTC-SVM and compared it to the classic DTC for a multi-drive EV propulsion system. The results of the simulation show the major importance of the effectiveness of the developed method which can mitigate some inconvenience related to the torque ripple and stator flux. The peculiarity of this work relied on the use of the proportional integral (PI) controller and switching table, which have been replaced by the hysteresis controller. However, there is a weakening of the battery, which causes heating around the conductors supplying motors and consequently impacts its life span. Nasri et al. [14] propose a sliding mode control technique for four wheels electric vehicle where each wheel consists of an asynchronous motor. The motors are each powered by a power converter and controlled independently by an electronic differential. The proposed control is compared to that of a classical PI controller. The results obtained show a rejection of disturbances and a good setpoint tracking. However, the presence of four converters and the fact that each motor is associated with a fixe ratio gearbox to increase the mass torque increases the volume and complexity of the propulsion system.

In recent years, artificial intelligence techniques have been introduced into the control of electric drive systems. They arouse a lot of interest due to their efficiency and power. Thus, Karima et al. in [15], neuro-fuzzy control by the indirect orientation of rotor flux is introduced. The proposed propulsion system is a two-wheel drive system whose speeds are independently controlled by an electronic differential and taking into account the given road profile. The simulation results obtained are satisfactory based on technical performances such as speed control and traction force. But, the realization of such a device remains complex because of control system design and architecture, which depends on engine parameters able to affect the stability of EV. Karima et al. [16] provides the beginning of a solution to this observed instability of EV. The authors have proposed a method of adaptive fuzzy reasoning with compensatory fuzzy operations. This method increases handling efficiency and stability under various road stresses of the propulsion system. It can be observed the complexity of the algorithm developed. In the works presented by Matéké et al. [11], the implementation of the SVM-DTC command and DTFC command for the twin-engine vehicle was carried out, the results showed that the association of fuzzy logic with direct command torque offers better performance in terms of speed, robustness, and energy savings compared to the SVM-DTC control. However, powering each of the motors by a converter is quite expensive and increases the size of the traction system.

In this sense, systems have been developed with several machines fed by a single converter in order to reduce the cost and size of the system. For example, the work of Sekour et al. [17] presents an approach to longitudinal control achieved by acceleration slip regulation and antilock braking system, based on direct torque control combined with the nonlinear predictive system for multi-machine system. This combination results in a high-performance torque control for EVs. The authors use the fuzzy logic technique to determine the exact values of the weighting factors online and generate the optimal switching states that optimize the EV drives. The complexity of the proposed control system remains a major drawback, especially when prototyping is required. Taibi et al. in [18], have developed a control strategy based on the conventional DTC technique for the control of 04 permanent magnet synchronous motors for the wheels of the electric vehicle. Motors on each side of the vehicle are powered by a single converter for a total of 02 three-phase inverters instead of 04 . This system is based on a master-slave control strategy switchable between machines and using the model reference adaptive system for speeds, which is effective despite once again high oscillations of the electromagnetic torque and stator flux.

The present study proposes to evaluate two methods of direct torque control (DTC) for multimachine systems used in electric vehicle traction chains. The DTC method associated with the model reference adaptive system (MRAS) for speed control and the VMSC system for the management of magnetic quantities of induction motors was developed based on the previous work Taibi et al. [18]. In order to provide an effective response to the difficulties caused by the previous method and work carried out by Matéké et al. [11], conventional DTC has been associated with the fuzzy logic technique and the VMSC system. The above-mentioned method differs from the previous ones by the use of control and management mechanisms such as PI regulator for speed control and an electronic differential (ED), in order to obtain better flexibility, speed, more precision, and simplicity of implementation. The performances obtained through the simulations indicate its adaptability to the use of multi-machine systems. 


\section{COMPONENTS OF THE ELECTRIC VEHICLE} their models.

In this part, a review of different components used for the traction chain designs is given based on

\subsection{EV dynamics}

The architecture of the EV developed in this paper is a twin-engine EV as shown in Figure 1. It contains key components of the conventional EV.

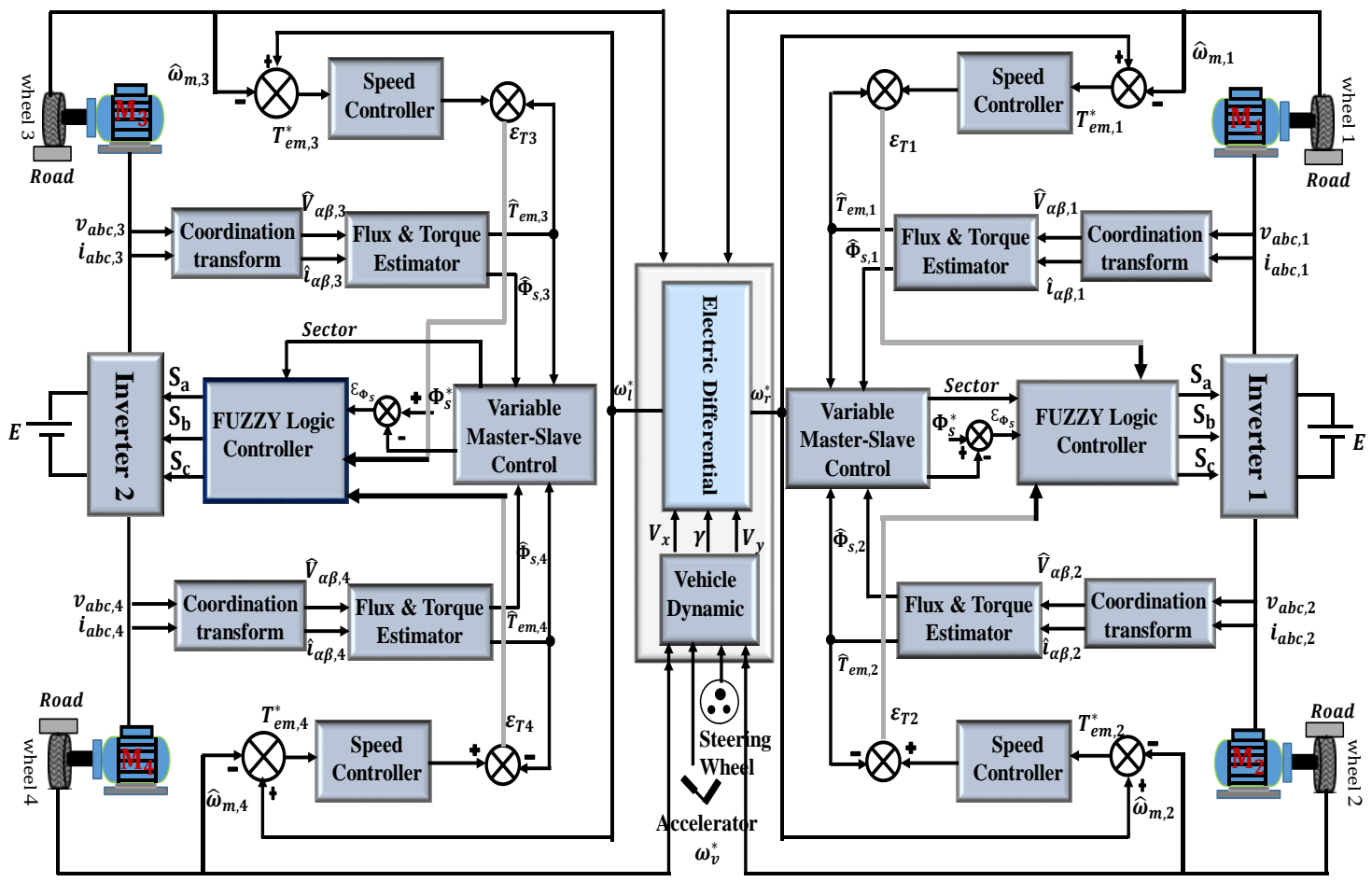

Figure 1. The architecture of the EV under investigation as [19], [20]:

Dynamics of the vehicle are described by yaw rate, and speed both longitudinal and lateral is being

$$
\begin{aligned}
& v_{x}=v_{y} r+\frac{F_{t 1}+F_{t 2}+F_{t 3}+F_{t 4}-F_{t o t}}{M_{v}}+\frac{C_{f} \delta}{M_{v}}\left(\frac{v_{y}+r l_{r}}{v_{x}}-\delta\right) \\
& v_{y}=\left(-\frac{C_{r}+C_{f}}{M_{v} v_{x}}\right) v_{y}+\left(\frac{C_{r} l_{r}+C_{f} l_{f}}{M_{v} v_{x}}-v_{x}\right) r+\frac{C_{f}}{M_{v}} \delta \\
& r=\left(\frac{C_{r} l_{r}-C_{f} l_{f}}{J_{v} v_{x}}\right) v_{y}-\left(\frac{C_{r} l_{r}^{2}-C_{f} l_{f}^{2}}{J_{v} v_{x}}\right) r+\frac{C_{f} l_{f}}{J_{v}} \delta+\frac{d}{J_{v}}\left(F_{t 1}+F_{t 2}-F_{t 3}-F_{t 4}\right)
\end{aligned}
$$

When analyzing Figure 2 different forces applied to the vehicle are mentioned for a better understanding. Then, (4) indicating the EV resistance opposes to any movement can be easily carried out. Following forces, the tire rolling resistance $\mathrm{F}_{\text {roll }}$, aerodynamic resistance in drag $F_{\text {aero }}$, leveling resistance $F_{\text {slope }}$, and acceleration resistance $F_{a c c}$ are needed for a calculation of the required total force all these resistances are discussed detailly in [21], [22].

$$
F_{\text {tot }}=F_{\text {roll }}+F_{\text {aero }}+F_{\text {slope }}+F_{\text {acc }}
$$

where

$$
\text { Froll }=\text { gMv } \operatorname{Crr} \cos \alpha
$$




$$
\begin{aligned}
& F_{\text {aero }}=0,5 \rho S_{f} C_{p x}\left(V_{h}-V_{\text {air }}\right)^{2} \\
& F_{\text {slope }}=g M_{v} \sin \alpha \\
& F_{\text {acc }}=\gamma M_{v}
\end{aligned}
$$

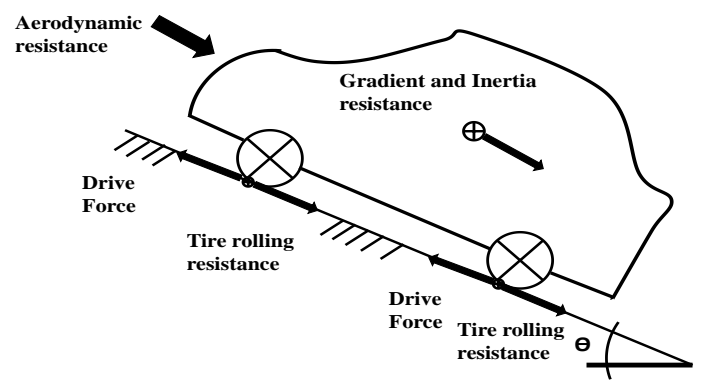

Figure 2. Forces on the vehicle

The longitudinal forces of four-wheel motors can be calculated using the (9) [18]:

$$
F_{t i}=\frac{\delta M_{v}}{4} \mu_{i} \cos \left(\alpha_{p}\right), i \in[1, \ldots, 4]
$$

The model of drive system can be described as shown in [18]:

$$
\begin{aligned}
& T_{r i}=F_{t i} R_{\omega}-N_{f} d_{z}, i \in[1,3] \\
& T_{r i}=F_{t i} R_{\omega}-N_{r} d_{z}, i \in[2,4]
\end{aligned}
$$

Where Tri is the resistive couple; $N_{f} N_{r}$, are normal front and rear forces calculated using the following expressions [18]:

$$
\begin{aligned}
& N_{f}=\frac{g M_{v}}{2}\left(\frac{l_{r}}{L}-\frac{h_{c g}}{L_{g}} * \frac{d v_{c g}}{d t} \alpha_{p}-\frac{h_{c g}}{L} \alpha_{p}\right) \\
& N_{r}=\frac{g M_{v}}{2}\left(\frac{l_{r}}{L}+\frac{h_{c g}}{L_{g}} * \frac{d v_{c g}}{d t} \alpha_{p}+\frac{h_{c g}}{L} \alpha_{p}\right)
\end{aligned}
$$

With a linear tire model, front and rear cornering forces can be expressed as the product of the cornering stiffness. $\left(C_{f}, C_{r}\right)$ and sideslip angle $\left(\alpha_{f}, \alpha_{r}\right)[18]$ :

$$
\begin{aligned}
& F_{y f}=-C_{f} \alpha_{f} \\
& F_{y r}=-C_{r} \alpha_{r}
\end{aligned}
$$

Sideslip angles of the wheels are expressed using the side length and angular speeds, as well as the steering angle $\delta$. The explicit expressions of sideslip angle for front and rear axles are represented by (17) [18].

$$
\begin{aligned}
& \alpha_{f}=\tan ^{-1}\left(\frac{v_{y}+l_{f} r}{v_{x}}\right)-\delta \\
& \alpha_{r}=\tan ^{-1}\left(\frac{v_{y}-l_{r} r}{v_{x}}\right)
\end{aligned}
$$

The longitudinal slip needs to be determined for all four wheels as:

$$
\lambda_{i}=\frac{R_{\omega} \omega_{i}-u_{t i}}{\max \left(R_{\omega} \omega_{i}-u_{t i}\right)}, i \in[1, \ldots, 4]
$$


Where:

$\mathrm{i}=1,2,3$ and 4 correspond to front left, front right, rear left and rear right $(=l f, f r, r l, r r)$ wheels, respectively; $\mathrm{R} \omega$ is the radius of the wheel; $\omega \mathrm{i}$ is the angular speed of the motor in the wheel, and $V$ is the linear speed at which the contact zone moves on the ground. Interrelationships between slip ratio $\lambda$ and the traction coefficient $\mu$ can be described by various formulas. In this study, the widely adopted magic formula [11], [23] is applied to describe the relationship between sliding and tensile forces in order to build a vehicle model in which the following simulations are indicated by as shown in (19) [24], [25].

$$
\mu=C_{1}\left[\sin \left(C_{2} \tan ^{-1}\left(C_{3} \lambda-C_{4}\left(C_{3} \lambda-\tan ^{-1}\left(C_{3} \lambda\right)\right)\right)\right)\right]
$$

The sets of coefficients of C1, C2, C3 and C4 are defined in [26], [27].

\subsection{Traction motor}

The dynamics of the induction machine are such that the expression of its torque is a function of the windings (stator and rotor) currents and the position of the rotor [11], [23]:

$$
\dot{X}=A X+B U
$$

$$
\begin{gathered}
\dot{X}=\left[\begin{array}{c}
I_{s \alpha}^{\cdot} \\
\dot{I_{s \beta}} \\
\dot{\emptyset_{r \alpha}} \\
\dot{\emptyset_{r \beta}}
\end{array}\right] B=\left[\begin{array}{cc}
\frac{1}{\sigma L_{s}} & 0 \\
0 & \frac{1}{\sigma L_{s}} \\
0 & 0 \\
0 & 0
\end{array}\right] U=\left[\begin{array}{c}
V_{s \alpha} \\
V_{s \beta}
\end{array}\right] \mathrm{X}=\left[\begin{array}{c}
I_{s \alpha} \\
I_{s \beta} \\
\emptyset_{r \alpha} \\
\emptyset_{r \beta}
\end{array}\right] \\
A=\left[\begin{array}{ccc}
-\frac{1}{\sigma L_{s}}\left(R_{S}+\frac{L m^{2}}{T r \cdot L r}\right) & 0 \frac{1}{\sigma L_{s}}\left(\frac{L m}{T r \cdot L r}\right) & \frac{1}{\sigma L_{s}}\left(\frac{L m}{L r}\right) \omega \\
0 & -\frac{1}{\sigma L_{s}}\left(R_{s}+\frac{L m^{2}}{T r \cdot L r}\right)-\frac{1}{\sigma L_{s}}\left(\frac{L m}{L r}\right) \omega & \frac{1}{\sigma L_{s}}\left(\frac{L m}{T r \cdot L r}\right) \\
\frac{L m}{T r} & 0-\frac{1}{T r} & -\omega \\
0 & \frac{L m}{T r} \omega & -\frac{1}{T r}
\end{array}\right]
\end{gathered}
$$

The electromagnetic torque in the referential $\alpha \beta$ can be expressed is being as [23]:

$$
C_{e m}=\frac{3}{2} p \frac{L m}{L_{r}}\left(\emptyset_{r \alpha} \cdot I_{s \beta}-\emptyset_{r \beta} \cdot I_{s \alpha}\right)
$$

While, the mechanical equation is written [11], [28]:

$$
J \frac{d \Omega}{d t}=C_{e m}-C_{r}-C_{f}
$$

With $\Omega=\frac{\omega}{p}$

Where $\mathrm{L}_{\mathrm{s}}, \mathrm{L}_{\mathrm{r}}, \mathrm{L}_{\mathrm{m}}, \mathrm{R}_{\mathrm{s}}, \mathrm{R}_{\mathrm{r}}, \mathrm{T}_{\mathrm{r}}, \mathrm{p}$ are stator inductance, rotor inductance, mutual inductance, stator resistance, rotor resistance, rotor time constant and the number of pole pairs, respectively.

\subsection{Inverter}

The two-voltage level inverter has been used for the proposed propulsion EV system. This inverter will give balanced alternating currents at variable frequencies. The voltages generated are given in the following matrix form [11]:

$$
\left[\begin{array}{l}
V_{a n} \\
V_{b n} \\
V_{c n}
\end{array}\right]=\frac{1}{3} U_{d c}\left[\begin{array}{ccc}
2 & -1 & -1 \\
-1 & 2 & -1 \\
-1 & -1 & 2
\end{array}\right]\left[\begin{array}{l}
S_{a} \\
S_{b} \\
S_{c}
\end{array}\right]
$$

Where $S_{a}, S_{b}, S_{c}$ are logical switches values and can be determined using several technics such as numerical, analogic, and other. 


\subsection{Modeling of the electronic differential (ED)}

The ED allows the management of the driving wheel speeds of the EV. On a straight path, it maintains the two speeds of the driving wheels at the same value. And for a curvilinear trajectory, depending on whether we are going left or right, it allows the speed of the wheel at the outside position of the curve to be greater. This prevents the tires from losing traction [16]. Figure 3 shows the EV depicting a curve. The notations $L_{w}, d_{w}$ and $\delta$ represent the wheelbase, the distance between driving wheels and the steering angle, respectively. The speeds $\omega_{R}^{*}$ and $\omega_{L}^{*}$ are the drive speeds of right and left motors.

So when:

$\delta>0 \rightarrow$ Turn right

$\delta=0 \rightarrow$ Straight ahead

$\delta<0 \rightarrow$ Turn left

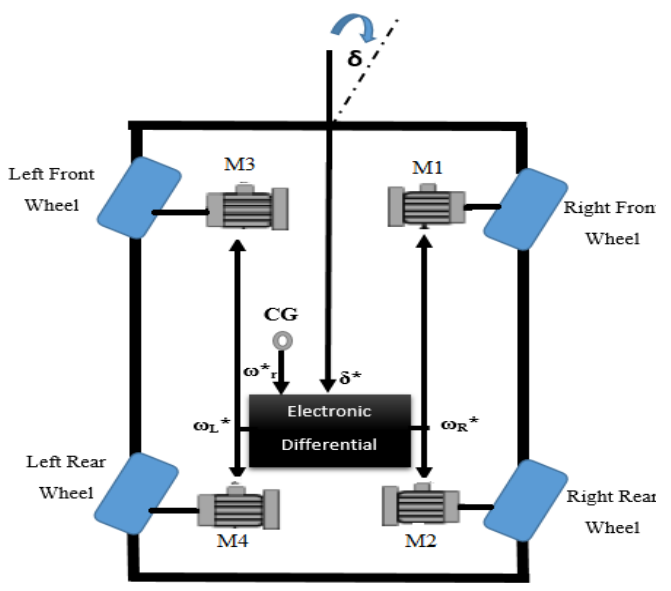

Figure 3. Structure of the electronic differential [11], [16]

It is possible to determine the reference speeds in relation to the driver's requirements. When the vehicle arrives at the start of a path, the driver applies a steering angle on its wheel [6], [11], [16], [29]. The ED acts instantly on both motors, reducing the speed of the wheel drive located at the inside position of the curve, thus increasing the speed of the driving wheel outside the curve. The angular speeds of the driving wheels are given by the relations:

$$
\begin{aligned}
& \omega_{R}^{*}=\left(\frac{V_{h}}{R_{\omega}}-\frac{\Delta \omega}{2}\right) \\
& \omega_{L}^{*}=\left(\frac{V_{h}}{R_{\omega}}+\frac{\Delta \omega}{2}\right)
\end{aligned}
$$

The difference between the angular speeds of the driving wheels can be expressed by [5], [10], [14]:

$$
\Delta \omega=\frac{d_{w} \tan (\delta)}{L_{w}} \cdot \frac{V_{h}}{R_{\omega}}
$$

with $L_{w}=L_{f}+L_{r}$

\subsection{Variable master slave control (VMSC)}

This is a switchable master-slave control strategy. In our system, it makes it possible to regulate the stator flux of machines placed in parallel. This is because the power to these machines is provided by a single converter, and it may happen that these machines do not undergo the same loads. This implies that the functioning of some can hamper that of others (for example, the magnetic circuit of one machine can become saturated without that of the other). To avoid this, a means must be found so that voltage vectors delivered by the converter supply each machine equitably by enabling it to develop speeds and torques which are respectively required of them. The flowchart in Figure 4 gives a perfect illustration of the role that VMSC plays in controlling such a training system. 
In our case, it is a matter of regulating the stator flux of one machine at a time. This machine will be called master and thus makes the other a slave. While the stator flux of the master machine is controlled, that of the slave machine evolves naturally without respecting the set point to avoid saturation. The master machine is the one with the lowest torque. We, therefore, observe that when the torque of a machine increases, its stator flux decreases and vice versa.

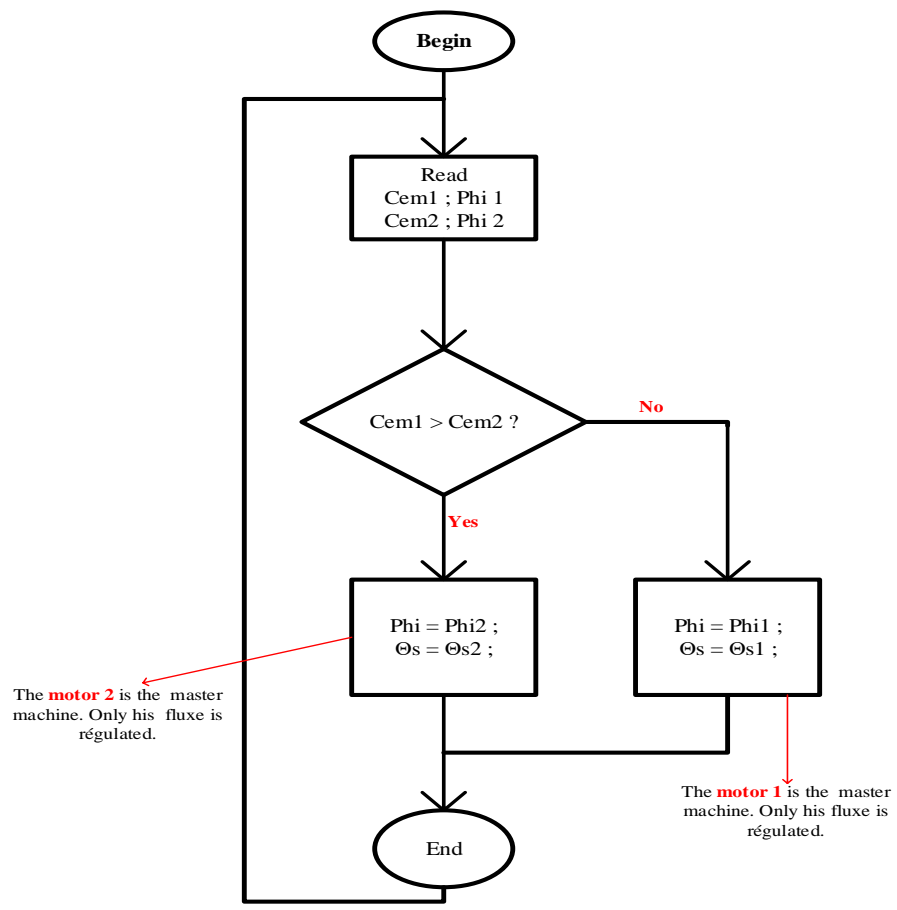

Figure 4. VMSC flowchart

\section{DEVELOPMENT OF THE PROPOSED CONTROL TECHNIQUE}

The control technique proposed in this article is the DTC associated with fuzzy logic. The block diagram of this command (DTFC) for a multi-machine system is shown in Figure 1 above. The fuzzy regulator includes 4 inputs which are:

- $e_{\varphi}$ : Difference between the reference stator flux and the estimated stator flux.

- $e_{T e m 1}$ : Difference between the reference torque and the electromagnetic torque of motor 1.

- $e_{\text {Tem2 } 2}$ : Difference between the reference torque and the electromagnetic torque of motor 2.

$-\theta_{s}$ : Position du vecteur de flux statorique.

The stake around the control for multi-machine systems with one converter is to ensure the optimal functioning of the actuators in parallel. Indeed, it must be ensured that the converter provides an adequate voltage vector to meet the demands of the machines. Thus, just like the conventional DTC command applied to this type of system, the DTFC command comprises in its structure a control loop as shown in Figure 5 of an electromagnetic torque regulation based on a Mandani type fuzzy regulator.

Thus, it includes two inputs:

$$
\begin{array}{ll}
- & e_{T e m 1}=T_{e m_{R e f 1}}-T_{e m 1}^{*} \text { for motor } 1 \\
- & e_{T e m 2}=T_{e m_{R e f 2}}-T_{e m 2}^{*} \text { for motor } 2
\end{array}
$$

And an exit

$$
-e_{\text {Tem }}
$$

The universe of discourses for each set is represented is being as: For $e_{\varphi}$ we have: $\mathrm{N}$ (negative) and $\mathrm{P}$ (positive).

For $e_{\text {Tem } 1}, e_{\text {Tem2 }}$ we have: $\mathrm{N}$ (negative), $\mathrm{Z}$ (zero), and $\mathrm{P}$ (positive). 
Trapezoidal and triangular membership functions were chosen. The torque error entry is made up of three fuzzy sets: $\mathrm{N}$ (negative), $\mathrm{Z}$ (zero) and $\mathrm{P}$ (positive) as shown in Figure 6 as shown in. This fuzzy regulator is governed by all the rules set out in the Table 1 as shown in.

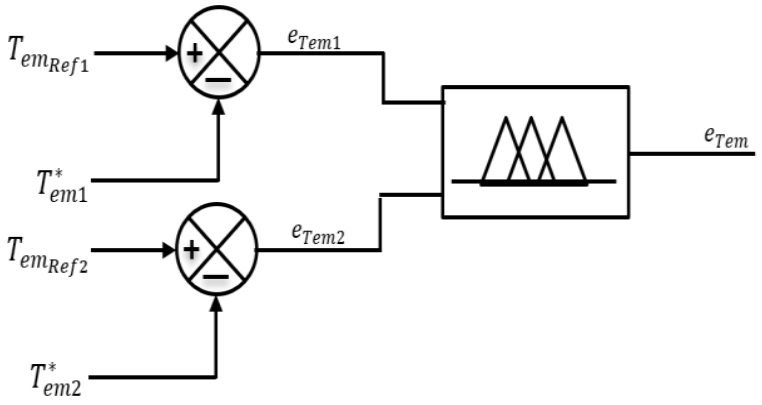

Figure 5. Structure of a fuzzy regulator for a multimachine system

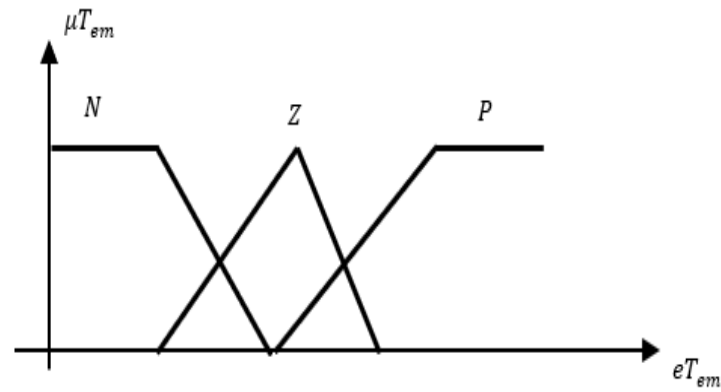

Figure 6. Membership function of torque error

Table 1. Basis of adopted rules

\begin{tabular}{llll}
$e_{\text {Tem } 2}$ & \multicolumn{3}{c}{$e_{\text {Tem1 }}$} \\
& $\mathrm{P}$ & $\mathrm{Z}$ & $\mathrm{N}$ \\
\cline { 2 - 4 } $\mathrm{P}$ & $\mathrm{P}$ & $\mathrm{P}$ & $\mathrm{Z}$ \\
$\mathrm{Z}$ & $\mathrm{P}$ & $\mathrm{Z}$ & $\mathrm{N}$ \\
$\mathrm{N}$ & $\mathrm{N}$ & $\mathrm{N}$ & $\mathrm{N}$ \\
\hline
\end{tabular}

The output obtained will be used for the selection of the adequate voltage vector by another fuzzy regulator with as other inputs:

- $\quad$ The stator flux error;

- The position of the stator flux vector $\theta_{s}$.

The position of the stator flux vector is subdivided into six sectors. And for the outputs, the pulse signals used for the selection of the voltage vectors by the inverter are $S_{a}, S_{b}$, and $S_{c}$ [20]. Thus, all the rules obtained for the new method proposed can be deduced from the principle of Table 1 as shown in.

\section{SIMULATION RESULTS}

The simulation parameters used in this article were chosen after an investigation in the literature. They come from the thesis work of [14] with prototyping but also of [10] and [15]. The vehicle model used is a fourwheel drive model of medium power, these simulation parameters correspond to this type of model to attest to the performance of EV. These performances are determined using the road constraints and the simulation parameters grouped in Table 2 and Table 3 applied to DTC associated with the MRAS system and DTFC techniques. Table 3. Shows the parameters of the two-pole asynchronous motor of power $37 \mathrm{KW}$ under $280 \mathrm{~V}$

Table 2. Electric vehicle parameters [18]

\begin{tabular}{lcc}
\hline \multicolumn{1}{c}{ Specification } & Symbol & Value \\
\hline Vehicle mass & $\mathrm{M}(\mathrm{Kg})$ & 1562 \\
Coefficient of air penetration & $C_{p x}$ & 0.25 \\
Coefficient of resistance to bearings & $C_{r r}$ & 0,001 \\
Air density & $\rho\left(\mathrm{Kg} / \mathrm{m}^{3}\right)$ & 1.2 \\
Front surface & $S_{f}\left(\mathrm{~m}^{2}\right)$ & 2.04 \\
Wheel radius & $R_{\omega}(\mathrm{m})$ & 0.294 \\
Moment of inertia of the vehicle & $J_{v}\left(\mathrm{Kg} \mathrm{m}^{2}\right)$ & 2630 \\
Wheel moment of inertia & $J_{w}\left(\mathrm{Kg} \cdot \mathrm{m}^{2}\right)$ & 1,284 \\
Distance between the front axle and the center of gravity & $L_{f}(\mathrm{~m})$ & 1,104 \\
Distance between the rear axle and the center of gravity & $L_{r}(\mathrm{~m})$ & 1,421 \\
Distance between the top of the vehicle and the center of gravity & $h_{c g}(\mathrm{~m})$ & 0,5 \\
Cornering stiffness for the front wheels & $N_{f}(\mathrm{~N} / \mathrm{rad})$ & 37407 \\
Cornering stiffness for the rear wheels & $N_{r}(\mathrm{~N} / \mathrm{rad})$ & 51918 \\
Distance between wheels & $d_{w}(\mathrm{~m})$ & 1,2 \\
\hline
\end{tabular}




\begin{tabular}{lcc}
\multicolumn{3}{c}{ Table 3. Motor parameters $[11]$} \\
\hline \multicolumn{1}{c}{ Specification } & Symbol & Value \\
\hline Nominal power & $\mathrm{P}(\mathrm{KW})$ & 37 \\
Nominal voltage & $\mathrm{V}(\mathrm{V})$ & 280 \\
Number of Pole Pair & $\mathrm{P}$ & 1 \\
Stator resistance & $\mathrm{R}_{\mathrm{s}}(\Omega)$ & 0,0851 \\
Rotor resistance & $\mathrm{R}_{\mathrm{r}}(\Omega)$ & 0,0658 \\
Stator inductance & $\mathrm{L}_{\mathrm{s}}(\mathrm{H})$ & 0,0314 \\
Rotor inductance & $\mathrm{L}_{\mathrm{r}}(\mathrm{H})$ & 0,0291 \\
Mutual inductance & $\mathrm{M}(\mathrm{H})$ & 0,0291 \\
Moment of inertia & $\mathrm{J}\left(\mathrm{Kg} . \mathrm{m}^{2}\right)$ & 0,23 \\
Nominal torque & $C_{\text {nom }}(\mathrm{Nm})$ & 241 \\
Rated speed & $\mathrm{n}(\mathrm{tr} / \mathrm{mn})$ & 2490 \\
Nominal power & $\mathrm{P}(\mathrm{KW})$ & 37 \\
Nominal voltage & $\mathrm{V}(\mathrm{V})$ & 280 \\
Number of Pole Pair & $\mathrm{P}$ & 1 \\
\hline
\end{tabular}

\subsection{Simulation of DTC associated with the MRAS system and DTFC for multi-machine systems}

Before implementing the DTC command applied to multi-machine systems, it is first desirable to evaluate the performance of this strategy through a simple test. Both conventional DTC commands are associated with the MRAS and VMSC assembly then the DFTC command with the VMSC has been implemented and the results are shown in. Torques of loads are applied at different times to two induction motors supplied by the same inverter on the same side of the vehicle as shown in Figure 7 . Thus between 0.4 $\mathrm{s}$ and $0.8 \mathrm{~s}$ motor 1 is subjected to the load of $30 \mathrm{~N} . \mathrm{m}$, between $1.2 \mathrm{~s}$, and $1.6 \mathrm{~s}$ engine motor 2 is subjected to an identical load. We observe that the master machine is the one that provides the highest torque. Figure 7 shows that whatever the values of the torques supplied to the motors, the system is stable. In DTC control associated with the MRAS system or in DTFC, the results are identical, proof that these two control methods are satisfactory for such applications.

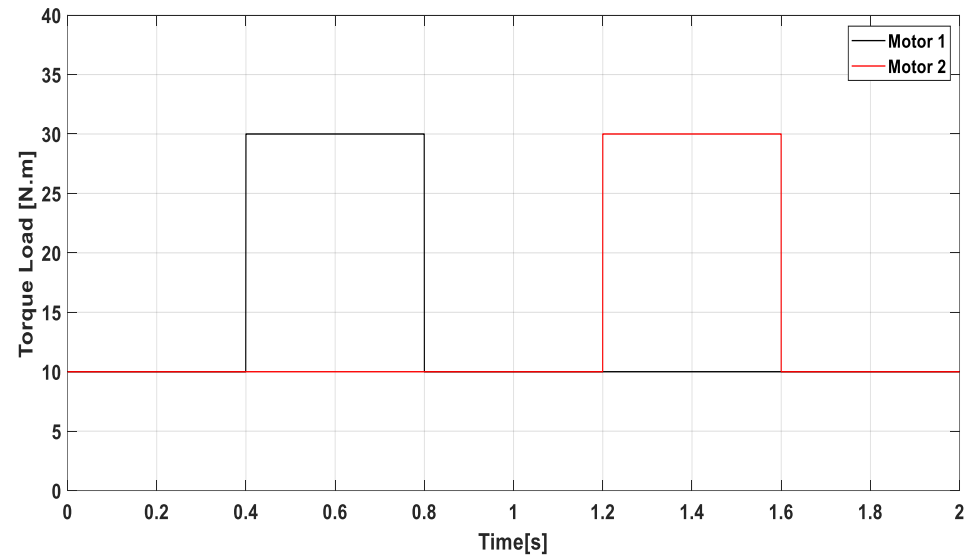

Figure 7. Load torques

Figure 8 shows the speed of different motors, which are regulated thanks to the MRAS system on the one hand (Figure 8 (a)) and the fuzzy logic controller on the other hand (Figure 8 (b)). It is observed that speeds, regardless of the command, follow the reference set at $100 \mathrm{rad} / \mathrm{s}$ relatively well for this test whatever the load applied. A faster response is observed for the DTFC command (Figure 8 (b)) compared to the conventional DTC associate with the MRAS system (Figure 8 (a)). The speed difference gives a satisfactory rate, proof that the exchange between the master motor, and the slave motor is carried out with great precision despite the disturbances observed on the control side.

Naturally, for a command based on direct torque and flux control, there is a rapid dynamic response of the electromagnetic torque. Each of the motors develops torque corresponding to the imposed load. The results obtained show that oscillations are stronger for the MRAS system (Figure 9 (a)) and weak for fuzzy direct control of the torque (Figure 9 (b)). This result is due to the proposed control algorithm which allows, 
in master or slave operation of the motors, to ensure the rapid response of the electromagnetic torque. The results of Figure 9 (b) show that the fuzzy logic approach reduces considerably these ripples.

Figure 10 shows the direct torque control in addition to obtaining a rapid response of torque and flow also allows excellent monitoring of references of these different sizes. The flow path along the alpha and beta axes describes a circle of unit radius that corresponds to $1 \mathrm{~Wb}$. There is a better resolution in DTFC than in DTC associated with MRAS as shown in Figure 10 (a)). Figure 10 (b) shows that the thickness of the circle in DTFC is much thinner than that in DTC associated with the MRAS system. DFTC control allows for reduced oscillations compared to the DTC control associated with the MRAS system. These fluxes have good magnetic stability, which guarantees good behavior fixed and imposed by the control strategy used (MRAS or fuzzy logic).

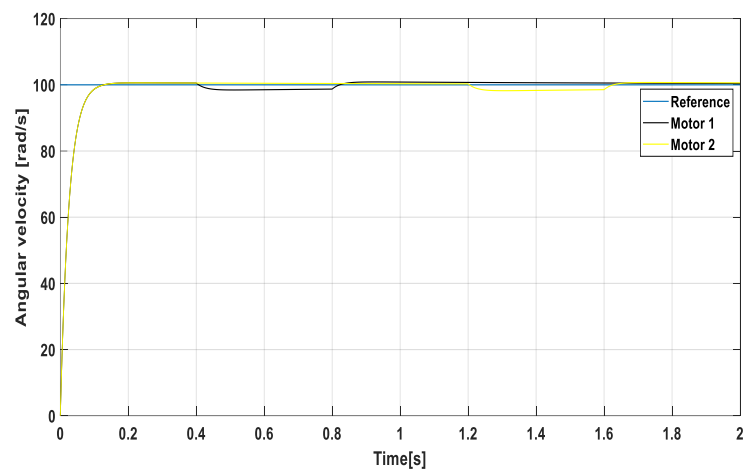

(a)

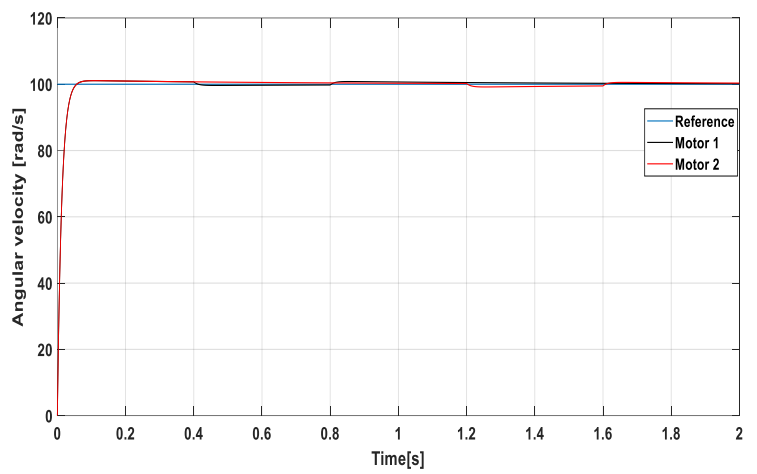

(b)

Figure 8. Angular speeds; (a) DTC_MRAS system, (b) DTFC

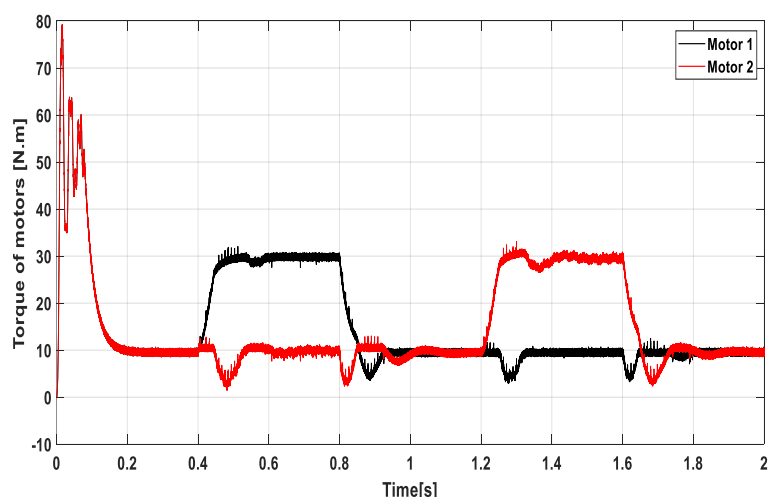

(a)

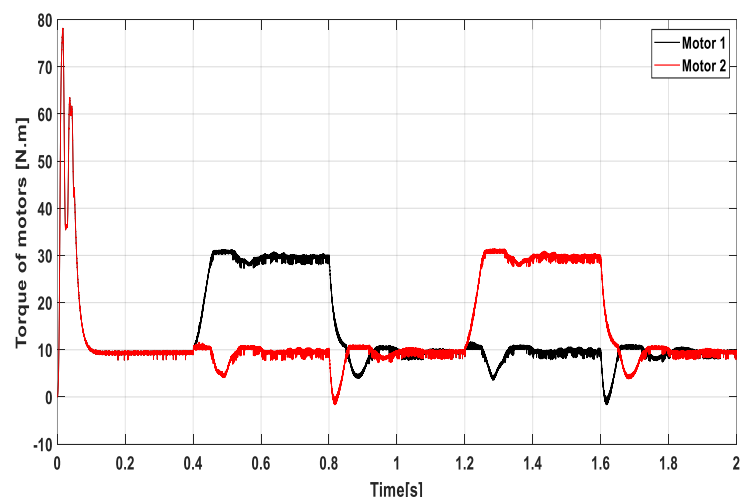

(b)

Figure 9. Electromagnetic torque; (a) DTC_MRAS system, (b) DTFC

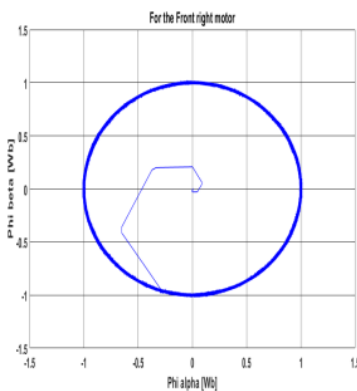

(a)

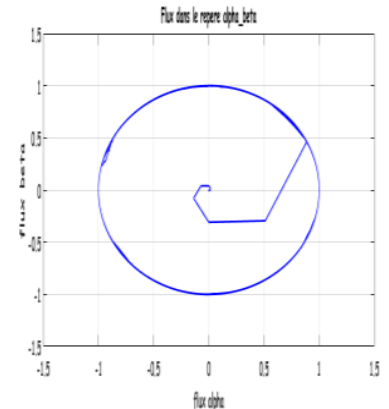

(b)

Figure 10. Stator flow modulus; (a) DTC_MRAS system, (b) DTFC 


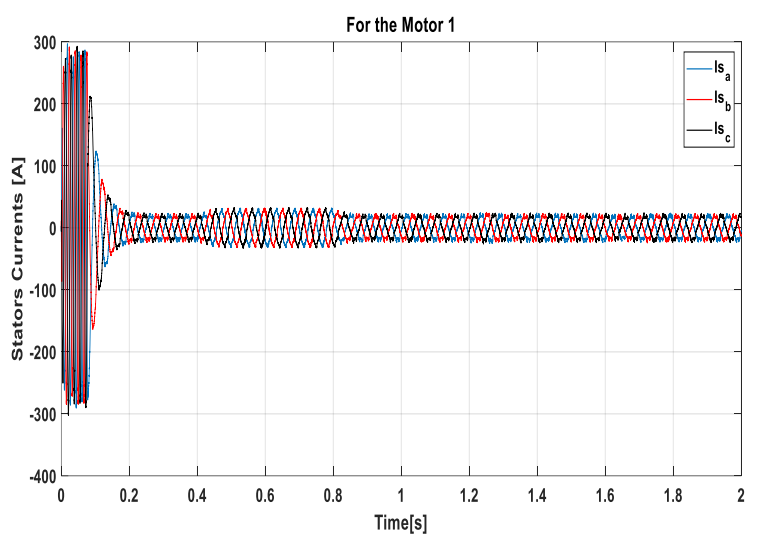

(a)

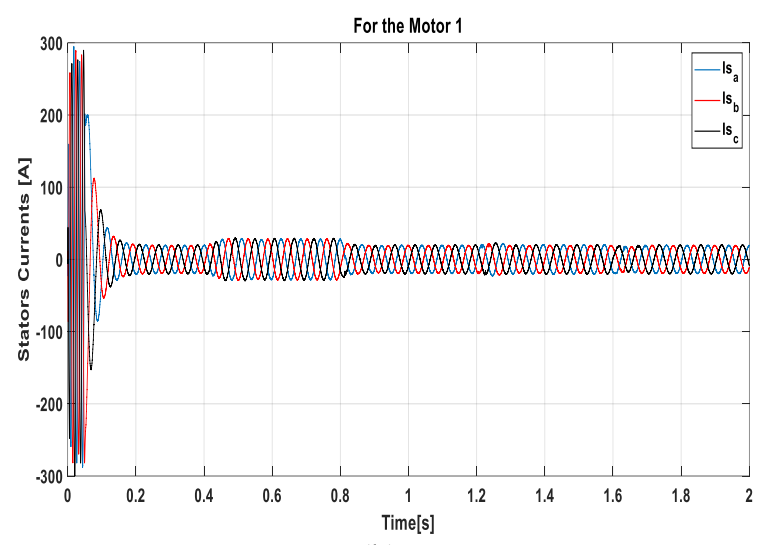

(b)

Figure 11. Stator currents for motor 1; (a) DTC_MRAS system, (b) DTFC

\subsection{Simulation of the proposed $\mathrm{EV}$ propulsion system}

The dynamics of a vehicle are defined by the driver through his actions on the accelerator pedal and the steering wheel. Here you can set the reference speed of the motors on the left as well as the right side and steering angle. A zero steering angle means that vehicle is traveling on a straight road and therefore the electronic differential does not act, the 04 engines run at the same speed. But otherwise, it means the vehicle is in a bend and distributes different torques and speeds between the inside and outside wheels in the bend to keep the EV stable.

For this test, the vehicle leaves a state of complete stop $(V=0 \mathrm{~m} / \mathrm{s})$ to reach its set speed from $\mathrm{t}=2 \mathrm{~s}$ $(\mathrm{V}=10 \mathrm{~m} / \mathrm{s})$ as shown in Figure 12 (a). A right turn is initiated from $\mathrm{t}=5 \mathrm{~s}$, the steering angle reaches its maximum value at $t=8 \mathrm{~s}$ and maintains it for $4 \mathrm{~s}$, then is canceled at $\mathrm{t}=15 \mathrm{~s}$ Figure $12(\mathrm{~b})$. It can be seen in Figure 12 (c) that during the turn the speeds of the inside wheels (right side) decrease while those of the outside wheels increase: this is the effect of the electronic differential. Despite the turn, we notice a good follow-up of the setpoint speed imposed by the driver with a longitudinal speed of the vehicle which seems similar to the speed of the vehicle according to Figure 12 (d). The lateral speed $V_{y}$ and the yaw moment $\mathrm{r}$ only comes into play during the turning phases as shown in Figure 12 (e).

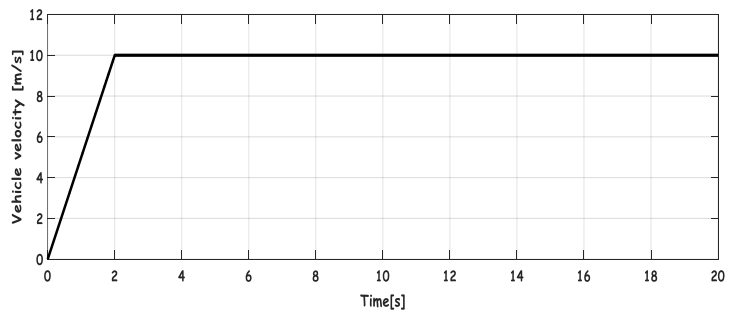

(a)

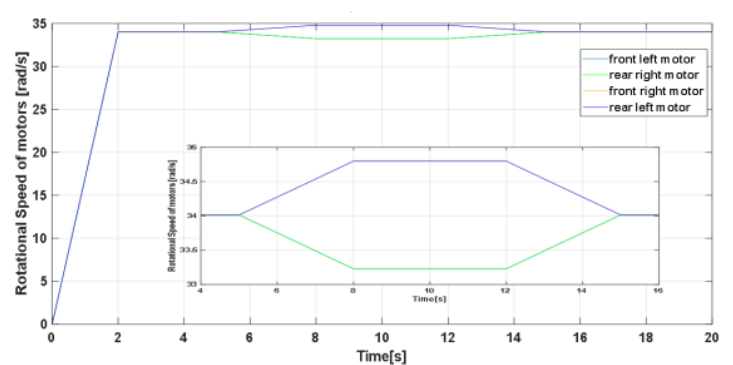

(c)

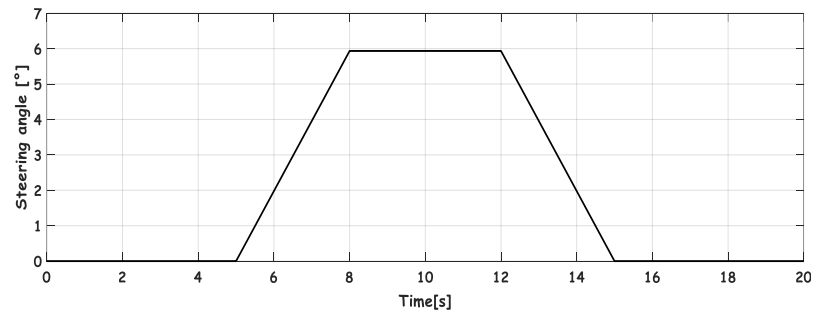

(b)

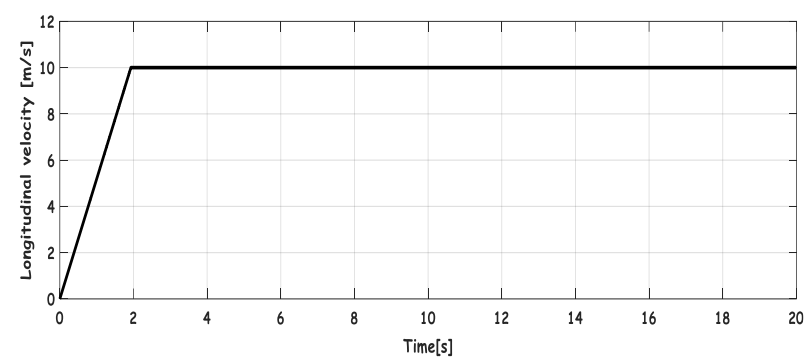

(d)

Figure 12. Dynamic quantities of the vehicle, (a) linear velocity of the vehicle, (b) steering angle input, (c) rotational speed of motors, (d) longitudinal velocity 


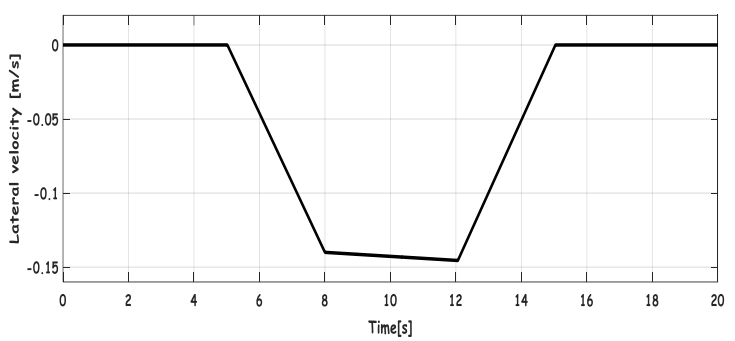

(e)

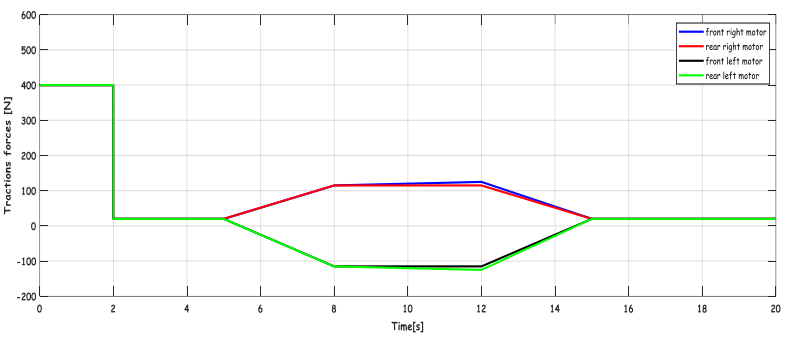

(f)

Figure 12. Dynamic quantities of the vehicle, (e) lateral velocity, (f) traction forces (continue)

To respond to the imposed stresses by the movement of the vehicle illustrated by Figure 12 (f) representing the requested traction forces, each motor develops the corresponding torque and this is observed in Figure 13. The motors provide high tractive forces to move the vehicle from the start. This seems normal since these forces must overcome the forces of overall resistance to the movement of the vehicle. This ensures the stability of the vehicle. This effect is observed for the two proposed control methods. With the turn being made on the right side, wheels on the same side must develop a higher torque because the weight of the vehicle shifts to the right. At the same time, we notice that wheels on the left side are being driven, where the torques of these motors become negative. It is observed that the oscillations are greater with a DTC command associated with the MRAS system in Figure 13(a) concerning the DTFC command in Figure 13(b).

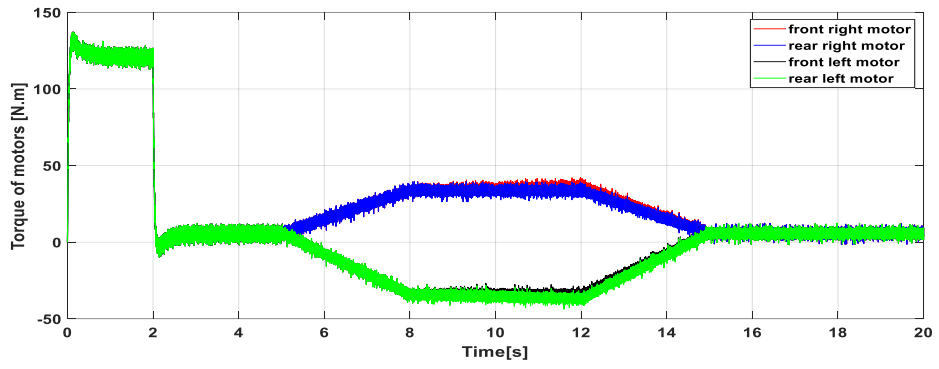

(a)

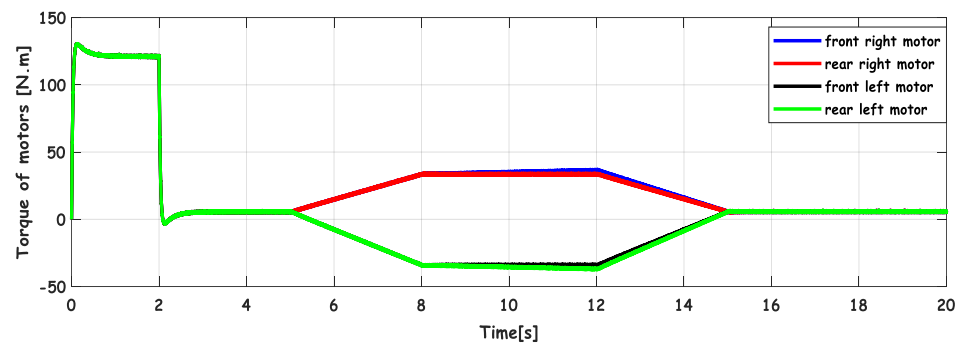

(b)

Figure 13. Torque of motors. (a) DTC_MRAS system, (b) DTFC

The stator fluxes of each of the machines follow their reference despite multiple variations in torque. Figure 14 (a) shows that the flux ripples are more important in DTC control associated with the MRAS system than in fuzzy logic control as shown in Figure 14 (b). The robustness of this control strategy is once observed because, in spite of the external disturbances, we notice a perfect follow-up. Figures 15 (a) and 15 (b) show the evolution of the stator currents absorbed by each motor for each control strategy used. Between 0 and $2 \mathrm{~s}$, this is the starting phase which is characterized by high current amplitudes reaching $80 \mathrm{~A}$. We see after this phase when the vehicle has reached its reference speed, the current amplitude stabilizes at $30 \mathrm{~A}$. During the turn, the currents follow the evolution of the electromagnetic torque developed by the corresponding motor until reaching a value of $50 \mathrm{~A}$. 


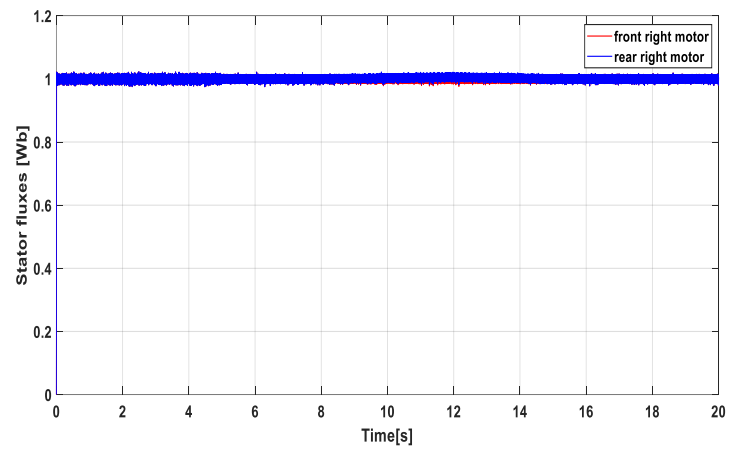

(a)

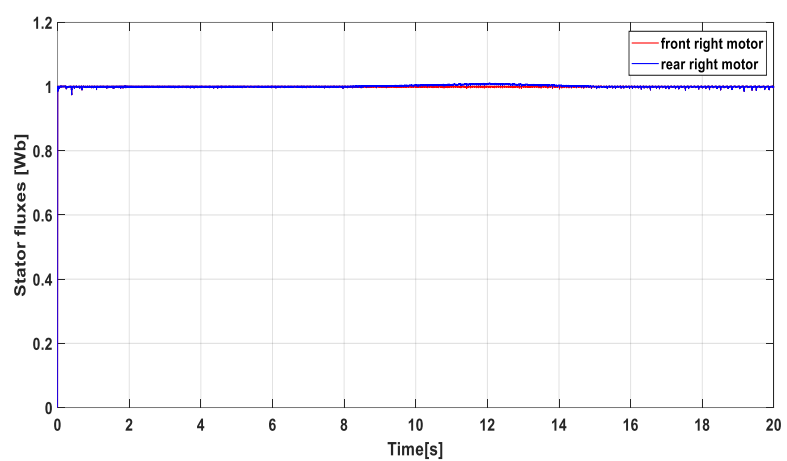

(b)

Figure 14. Stator flux, (a) DTC_MRAS system, (b) DTFC

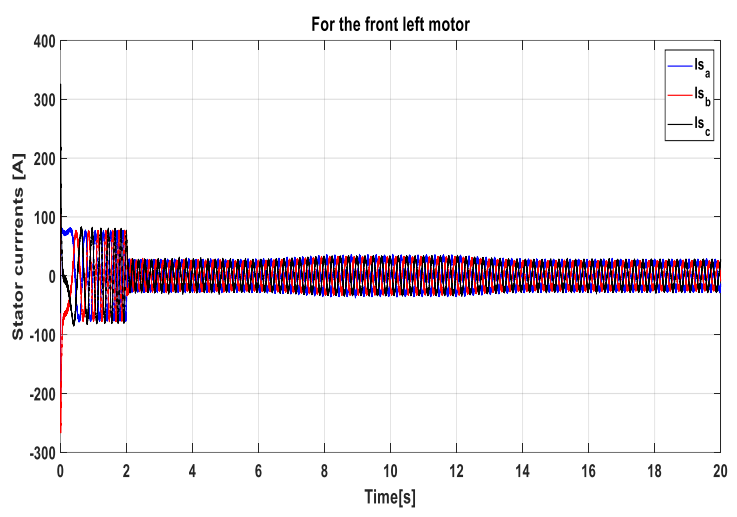

(a)

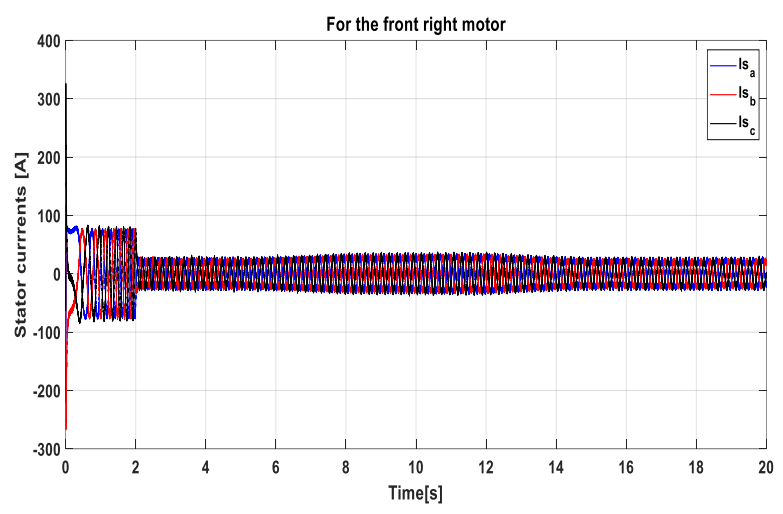

(b)

Figure 15. Stator currents for motor, (a) DTC_MRAS system, (b) DTFC

Figure 16 show the zoom in on the currents allows you to appreciate their good waveform. Looking at Figure 16 (a) we can see that it has much more polluted stator current waves than the current waves obtained by the fuzzy logic controller in Figure 16 (b). This makes it possible to reduce the vibrations of the motor shaft and noises which have the effect of reducing the life of the various engines while ensuring a certain comfort in the passenger compartment. This can justify his choice of the DTC method associated with the MRAS system.

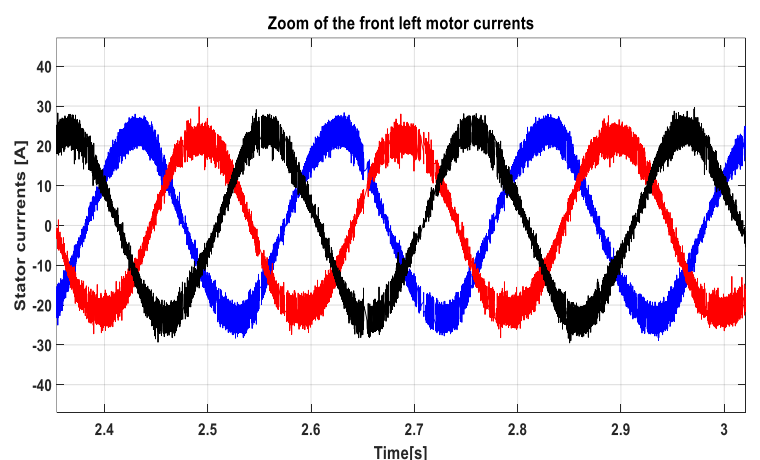

(a)

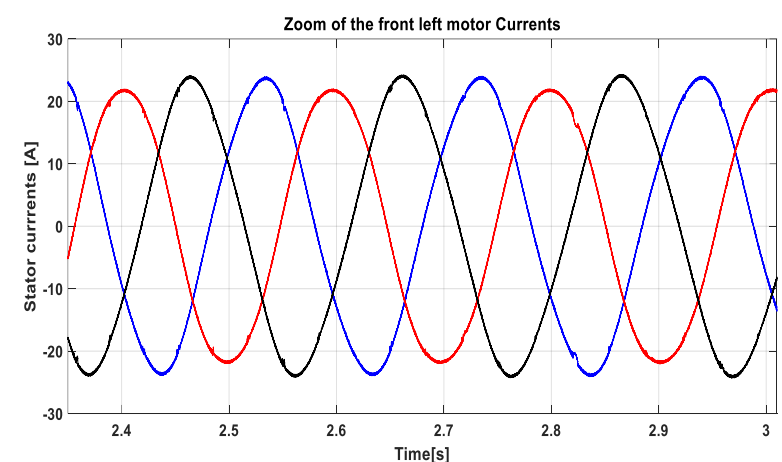

(b)

Figure 16. Zoom of stator currents for motor, (a) DTC_MRAS system, (b) DTFC 


\subsection{Comparative studies of the two controllers used}

The above simulations have shown two methods of controlling the driving wheels of an electric vehicle. The DTC associated with the MRAS system and DTFC controllers has proven their effectiveness in the dynamic stability control behavior of EVs under various imposed road constraints. To justify and observe the effect of disturbances on vehicle speed, both methods were used under the same conditions. Vehicle speed results are summarized in Table 4 as shown in:

DTFC control has a 1.4 percent reduction in rising time compared to the command DTC associated with the MRAS system. The command DTC associated with the MRAS system has a torque and flux amplitude oscillation of over 9 percent on the DTFC. The fuzzy controller has better performance than the MRAS system controller in terms of speed control efficiency. However, the two controllers allow the realization of modern control, with good dynamic performance. The advantage of the fuzzy controller is its robustness, its ability to maintain perfect trajectories for independently controlled driving wheels. But also, it ensures the discharge of disturbances of the road during the turning phases. The characteristics thus given for an electric powertrain are the key point of the propulsion systems of EVs.

Table 4. Performance of the DTC associate with the MRAS system and DTFC speed responses

\begin{tabular}{lccc}
\hline \multicolumn{1}{c}{ Type of controller } & Rising time [s] & Overshoot [\%] & Steady state error [\%] \\
\hline DTFC & 0,030 & 0,692 & 0,0010 \\
DTC associated with the MRAS system & 0,044 & 0,727 & 0,0016 \\
\hline
\end{tabular}

\section{CONCLUSION}

In this article, two methods of controlling multi-machine systems for the propulsion of EVs are proposed. The EV architecture chosen is that of four wheels each with an induction motor, using two static converters at two voltage levels to supply power to the motors. For the first method, DTC is associated with the MRAS system and VMSC for speed control and management of magnetic quantities. A performance improvement obtained by the first method is done via a DTC with a fuzzy logic approach. This second method combines the VMSC system and PI regulator for the management of magnetic quantities and speed control. The use of electronic differential makes it possible to manage engine speeds during turning, climbing, and descending phases. The simulation results show better adaptability of the second method for training multi-machine systems of electric vehicles.

\section{REFERENCES}

[1] B. Multon, "Electric vehicle motor sesi," (in French) Technique de l'ingénieur, Traité Électronique, E3996, 2001.

[2] M. H. Rashid, "Power Electronics Handbook," $4^{\text {th }}$ edition, Fellow IET (UK), Life Fellow IEEE, Florida Polytechnic University, USA, 2017.

[3] J. L. Afonso, et al., "A Review on Power Electronics Technologies for Electric Mobility," MDPI Journal Energies, vol. 13, no. 23, p. 6343, 2020, doi: 10.3390/en13236343.

[4] S. Soylu, "Electric Vehicles-Modelling and Simulation," Janeza trdine 9, 51000 Rijeka, Croatia, pp. 13-30, 2011.

[5] G. Banda and S. G. Kolli, "An Intelligent Adaptive Neural Network Controller for a Direct Torque Controlled eCAR Propulsion System,” World Electric Vehicle Journal, vol.12, pp1-17 Mar. 2021.

[6] A. Nasri and B. Gasbaoui, "A novel electric vehicle drive studies based on space vector modulation technique and direct torque control strategy," Journal of Asian Electric Vehicles, vol. 9, no. 2, pp. 1529-1535, 2011, doi: 10.4130/jaev.9.1529.

[7] K. Chau, "Electric Vehicle Machines and Drives: Design, Analysis and Application," John Wiley \& Sons: Hoboken, NJ, USA, 2015.

[8] A. Mustafa, A. Khaled, E. Mehrdad, and A. Aydemir, "Direct torque control versus indirect field-oriented control of induction motors for electric vehicle applications," Engineering Science and Technology, an International Journal, vol. 23, no. 5, pp. 1134-1143, 2020, doi: 10.1016/j.jestch.2020.04.002.

[9] K. M. Mohamed, et al., "Smart integration of drive system for induction motor applications in electric vehicles," International Journal of Power Electronics and Drive System (IJPEDS), vol. 12, no. 1, pp. 20-28, March 2021, doi:

[10] I. Takahashi and Y. Ohmori, "High-performance direct torque control of an induction motor," in IEEE Transactions on Industry Applications, vol. 25, no. 2, pp. 257-264, March-April 1989, doi: 10.1109/28.25540.

[11] M. N. Matéké, J. M. N. Yome, S. Eke, A. Biboum, and L. Bitjoka, "Electric Vehicle Wheel Drive Analysis Using Direct Torque Fuzzy Control Method,” Solid State Technology Journal, vol. 63 no. 5, pp. 4286-4295, 2020.

[12] K. Cakir and A. Sabanovic, "In-wheel motor design for electric vehicles," 9th IEEE International Workshop on Advanced Motion Control, 2006., 2006, pp. 613-618, doi: 10.1109/AMC.2006.1631730.

[13] S. Sakai, H. Sado, and Y. Hori, "Motion control in an electric vehicle with four independently driven in-wheel motors," in IEEE/ASME Transactions on Mechatronics, vol. 4, no. 1, pp. 9-16, March 1999, doi: $10.1109 / 3516.752079$. 
[14] A. Nasri, B. Gasbaoui, and B. M. Fayssal, "Sliding mode control for four wheels electric vehicle drive," Procedia Technology, vol. 22, pp. 518-526, 2016, doi: 10.1016/j.protcy.2016.01.111.

[15] K. Houacine, R. Mellah, S. Guermah, and M. Charif, "Neural fuzzy control of driving wheels for electric vehicle," 3rd International Conference on Systems and Control, 2013, pp. 25-30, doi: 10.1109/ICoSC.2013.6750830.

[16] H. Karima, M. Rabah, and G. Said, "Compensatory neural fuzzy control for two wheels electric vehicle drive," Int. J. Electric and Hybrid Vehicles, vol. 7, no. 2, pp. 189-207, 2015, doi: 10.1504/IJEHV.2015.071060.

[17] M. Sekour, K. Hartani, and A. Merah, "Electric Vehicle Longitudinal Stability Control Based on a New Multimachine Nonlinear Model Predictive Direct Torque Control," Hindawi Journal of Advanced Transportation, vol. 2017, 2017, doi: 10.1155/2017/4125384.

[18] T. Ahmed, H. Kada, and A. Allali, "New DTC strategy of multi-machines for electric vehicle transition applications," International Journal of Power Electronics and Drive System (IJPEDS), vol. 11, no. 2, pp 641-650, June 2020, doi: 10.11591/ijpeds.v11.i2.pp641-650.

[19] E. Esmailzadeh, G. Vossoughi, and A. Goodarzi, "Dynamic modeling and analysis of a four motorized wheels electric vehicle," Vehicle System Dynamics, vol. 35, no. 3, pp. 163-194, 2001, doi: 10.1076/vesd.35.3.163.2047

[20] M. Khalfaoui, K. Hartani, A. Merah, and N. Aouadj, "Development of shared steering torque system of electric vehicles in presence of driver behaviour estimation," International Journal of Vehicle Autonomous Systems, vol. 14, pp. 18-39, July 2018, doi: 10.1504/IJVAS.2018.093100.

[21] T. D. Gillespie, "Fundamentals of Vehicle Dynamics," Society of Automotive Engineers Inc.: Warrendale, PA, USA, 1992.

[22] J. Y. Wong, Theory of ground vehicles, John Wiley \& Sons, 2008.

[23] M. H. Sekour, K. Hartani, A. Draou, and A. Allali, "Sensorless fuzzy direct torque control for high performance electric vehicle with four in-wheel motors," Journal of Electrical Engineering and Technology, vol. 8, no. 3, pp. 530-543, 2013, doi: 10.5370/JEET.2013.8.3.530.

[24] K. Hartani, M. Khalfaoui, A. Merah, and N. Aouadj, "A Robust Wheel Slip Control Design with Radius Dynamics Observer for EV," SAE International Journal of Vehicle Dynamics, Stability, and NVH, vol. 2, pp. 135-146, 2018, doi: 10.4271/10-02-02-0009.

[25] K. Hartani, M. Bourahla, and Y. Miloud, "New antiskid control for electric vehicle using behaviour model control based on energetic macroscopic representation," Journal of Electrical Engineering, vol. 59, no. 5, pp. 225-233, 2008.

[26] R. Rajamani, "Vehicle dynamics and control," Springer Science \& Business Media, 2011

[27] H. B. Pacejka, and E. Bakker, "The magic formula tyre model," Vehicle system dynamics, vol. 21, no. S1, pp. 1-18, 1992, doi: 10.1080/00423119208969994.

[28] I. Koussaila, A. Bessam, O. C. Tahar, B. Mohamed-Fouad, A. Djamal, and G. Kaci, "Improved direct field oriented control of multiphase induction motor used in hybrid electric vehicle application," International Journal of Hydrogen Energy, Elsevier, vol. 42, no. 30, pp. 19296-19308, July 2017, doi: 10.1016/j.ijhydene.2017.06.195.

[29] A. Haddoun, M. E. H. Benbouzid, D. Diallo, R. Abdessemed, J. Ghouili, and K. Srairi, "Sliding mode control of EV electric differential system," ICEM, p. 6, 2006. [Online]. Available: http://hal.archives.ouvertes.fr. 